\title{
REGLAS DE JUEGO Y ORDEN CONSTITUCIONAL COMO REGLAS DE LA CONVIVENCIA
}

\author{
THE RULES OF THE GAME AND CONSTITUTIONAL \\ ORDER AS RULES OF COEXISTENCE
}

\author{
JuAn-Ramón Fallada-García-Valle \\ Universitat Rovira i Virgili
}

Fecha de recepción: 6-5-20

Fecha de aceptación: 13-10-20

Resumen: Algunas expresiones caracterizan el orden constitucional como las "reglas del juego" o "de convivencia". Este artículo explora algunas características fundamentales de los órdenes constitucionales a partir de su comparación con las reglas de los juegos. Libertad, carácter lúdico y ausencia de castigos para quienes deciden no jugar, se contraponen a supuesta aceptación compartida de las normas constitucionales, sacralidad y potencial uso de la violencia desregulada contra la disidencia. A partir de esa caracterización de los órdenes constitucionales, se hacen algunos comentarios críticos.

Abstract: Some expressions identify the constitutional order with the "rules of the game" or "of the convivence". Taking that as a starting point, some key characteristics of the constitutional orders are pointed out, by comparing them with the rules of the games. Freedom, ludic character and lack of punishment to those who decide not to play are confronted to supposed shared consent of the constitutional norms, sacredness and potential use of unregulated violence against dissidence. From that characterization some critical comments will be made.

Palabras clave: reglas de juego, orden constitucional, normas regulativas/ constitutivas, estado de excepción, estado de derecho, derecho a la autodeterminación

Keywords: rules of game, constitutional order, regulative/constitutive norms, state of exception, rule of law, right of self-determination 


\section{PLANTEAMIENTO DEL TEMA}

De las constituciones se suele afirmar que establecen las reglas de juego de una comunidad política o, también, las reglas de convivencia. Creo que lo que se está afirmando es que hay unas normas fundamentales teóricamente aceptadas y compartidas por sus miembros mediante las cuales una comunidad política se constituye y se define a sí misma. Este artículo pretende explorar los paralelismos (y las divergencias) entre las reglas de los juegos y el orden constitucional, entendido éste como el conjunto de normas dirigidas a posibilitar y articular la convivencia social.

No toda relación social es una relación de convivencia. Sin ánimo de exhaustividad, una relación de convivencia consistiría en una relación entre partes que se consideran iguales entre sí, basada en la voluntariedad, estable en el tiempo, amplia y compleja por el alcance de las actividades comunes, con objetivos compartidos por las partes, dando todo ello lugar a la constitución de una comunidad sustentada por lazos de afectividad.

Esos rasgos guardan relaciones entre sí. Por ejemplo, que las partes estén situadas en un plano de igualdad, consecuencia de un respeto recíproco, hace que la relación se base en la voluntariedad y contribuye a la formación de lazos afectivos. Con todo, de entre todos esos rasgos me centraré en los de la voluntariedad y la constitución de una comunidad, pues creo que resultan particularmente importantes para entender las semejanzas entre las relaciones de convivencia y las relaciones sobre las que se sustenta la actividad de jugar: tanto el convivir como el jugar pasan por aceptar someterse a las normas que regulan esos modos de relacionarse; por otro lado, quienes aceptan someterse establecen una relación que, por sus peculiaridades, conlleva la creación de una comunidad. Un objetivo central de este trabajo reside en mostrar la relevancia de esos dos elementos a la hora de mostrar las semejanzas y diferencias entre las reglas de los juegos y las normas constitucionales de las comunidades políticas.

Esta no es una cuestión extraña al pensamiento político o jurídico. El meollo del problema de la legitimación del poder político y la justificación del deber de obediencia al Derecho reside ulteriormente en que, quienes están sujetos a ese poder, acepten tal posición de sujeción. Diría que todas las ideologías políticas coinciden en sostener que el poder político queda legitimado y la obediencia al derecho justificado si actúa, no con miras al interés de los gobernantes o de algún otro grupo particular, sino al de la comunidad política. 
Un último comentario introductorio. La creencia en la idoneidad de la comparación entre reglas de los juegos y orden constitucional parte de ciertos presupuestos metodológicos. Por cuestiones de espacio y de delimitación del objeto de estudio, no se entrará ni en la exposición ni en el análisis de esa metodología, si bien se hacen ciertos apuntes al respecto en algunas notas a pie de página. Sólo un apunte muy general que, espero, ayude a la lectura de esas notas. Se parte aquí de una concepción del derecho no-formalista, pues se cree que el fenómeno jurídico está inextricablemente interrelacionado con la política. Tradicionalmente, esas interrelaciones han encontrado su lugar de máxima condensación en la noción de "soberanía", noción que conlleva la sacralización de la esfera de lo jurídico. Frente a esa manera tradicional de entender las relaciones entre derecho y política, aquí se lanza una propuesta alternativa que vigoriza las relaciones de lo jurídico y lo lúdico. El punto clave que, a mi entender, da cuenta de esa idoneidad radica en que la actividad de jugar consiste en una actividad libre sujeta a reglas (es decir, que el sometimiento a las reglas del juego parte de la previa aceptación), idea nuclear del principio democrático y, por ende, del Estado de derecho. Por esa vía, las relaciones entre política y derecho varían respecto a aquella comprensión tradicional: la política queda sujeta a la normatividad del derecho. Es dentro de ese marco donde el análisis formalista-normativista del derecho tomaría sentido y relevancia.

\section{SOBRE LAS REGLAS DE LOS JUEGOS}

\subsection{Normas constitucionales de las reglas de los juegos como nor- mas definitorias y constitutivas de una actividad lúdica y de una comunidad de jugadores}

A la hora de comparar las reglas de los juegos y los ordenamientos jurídicos, el Derecho se suele relacionar con aquellos juegos que Caillois situaría en la esfera del ludus en contraposición a la esfera de la paidia ${ }^{1}$. Esa recurrente ubicación del fenómeno jurídico en el terreno de lo ordenado resulta acertada en situaciones de normalidad, si bien será puesta en cuestión cuando, al

Ludus hace referencia a la acción calculada, meditada y subordinada a normas preestablecidas, mientras que con paidia se refiere a la acción proactiva, tumultuosa, exuberante y espontánea. Ver R. CAILLOIS, Man, play, and games, Urbana; Chicago, University of Illinois Press, [1958] 2001, p. 13. 
analizar en qué medida es correcta la analogía entre las normas constitucionales y las reglas de los juegos, se tenga en cuenta el fenómeno del estado de excepción, es decir, la suspensión del orden jurídico.

Todo reglamento de un juego se estructura estableciendo un objetivo o valor (de manera genérica, ganar la partida), una serie de reglas que determinan $^{2}$ y constituyen patrones fijos para los movimientos considerados correctos y que delimitan la manera de conseguir ese objetivo, una serie de reglas que ordenan la secuenciación de esos movimientos considerados correctos $\mathrm{y}$, finalmente, una serie de reglas que determinan los componentes necesarios para poder llevar a cabo esos movimientos considerados correctos. Las reglas de los juegos que cumplen alguna de esas funciones se denominarán "normas constitucionales".

Desde el punto de vista de las funciones del lenguaje, las normas constitucionales de un juego son aquellas normas que, desde una posición interna (más adelante se entrará en esta cuestión), cumplen, o bien la función de determinar la validez o nulidad -la posibilidad o la imposibilidad- de una acción a efectos del juego (función definitoria o determinativa) ${ }^{3}$, o bien la función de constituir o crear una acción encaminada a la consecución del objetivo marcado por el propio juego, de tal forma que, sin esas normas, la actividad en cuestión no existiría (función constitutiva).

En algunos casos, las reglas de los juegos se componen exclusivamente de normas constitucionales, como es el caso del ajedrez. En otros, como sucedería en el Monopoly, las reglas del juego incluyen tanto normas constitucionales como prescriptivas. Frente a las normas constitucionales, las normas prescriptivas (en sentido amplio) serían 1) aquellas que tienen la función de guiar la conducta mediante el establecimiento de permisos, obligaciones o prohibiciones, y cuyo incumplimiento, durante el normal desarrollo de la partida, conlleva la imposición de sanciones (normas prescriptivas en sentido estricto), y 2) también aquellas donde se recoge el deber de imponer una sanción en caso de haber incumplido con alguna norma prescriptiva del tipo anterior (normas de sanción).

Las normas constitucionales de las reglas de los juegos conforman sistemas normativos de validez conjunta y autónoma. Raz ${ }^{4}$ caracteriza este tipo

\footnotetext{
2 G. H. VON WRIGHT, Norma y acción, Madrid, Tecnos, 1970, p. 26.

3 G. H. VON WRIGHT, Norma y acción, cit., pp. 25-26. pp. 130-141.

4 J. RAZ, Razón práctica y normas, Madrid, Centro de Estudios Constitucionales, 1991,
} 
de sistemas como aquellos en que el incumplimiento de una sola de las reglas deja sin sentido el hecho de cumplir con las demás, lo cual equivale a afirmar que el incumplimiento de una norma implica dejar de llevar a cabo la actividad de jugar. En ese sentido, las normas constitucionales de las reglas de un juego constituyen conjuntamente la actividad de jugar a un juego.

"Jugador" es aquel agente que lleva a cabo una actividad lúdica regulada por las reglas de un juego, esto es, que asume como único valor el estipulado en las reglas y se rige por éstas para conseguir realizar el fin propuesto. Si la actividad no se realiza en solitario, los agentes que están llevando a cabo una misma actividad forman parte de una misma comunidad de agentes ${ }^{5}$ (o "comunidad de jugadores" en el caso de la actividad de jugar). Desde esta perspectiva, las normas constitucionales se pueden definir como aquellas normas que todos los agentes tienen que cumplir para que todos ellos estén realizando la misma actividad; inversamente, se trataría de aquellas normas cuyo incumplimiento implicaría que ya no todos estarían llevando a cabo la misma actividad. Respecto a las normas constitucionales de una actividad no cabe, en principio, el término medio: o bien se cumple con las reglas de juego, en cuyo caso se está llevando a cabo la actividad y se forma parte de la comunidad de agentes (o jugadores), o no se cumple con ellas y, entonces, no se está llevando a cabo la actividad, ni se forma parte de la comunidad de agentes (o jugadores). En consecuencia, en la medida en que el propósito sea que un determinado colectivo de agentes lleve a cabo la misma actividad, respecto al cumplimiento o no de las normas constitucionales se exige la unanimidad, sin que resulte admisible la disensión.

\subsection{Actividad lúdica como actividad voluntaria}

El juego es una actividad lúdica: si un juego no divierte, lo normal es que se deje de jugar $y$, tal vez, que no se vuelva a jugar ${ }^{6}$. Dejar de jugar tiene que ser siempre una opción ${ }^{7}$; en el momento en que no cabe la posibilidad de abandonar el juego, éste deja de serlo.

5 Se define "comunidad de agentes" como el grupo de personas que, voluntariamente, adecúan su comportamiento de manera generalizada y estable a las normas constitucionales de una actividad.

6 E. GOFFMAN, “Fun in games”, en Encounters, Indianapolis, Bobbs-Merril Company, 1961, pp. 17-81.

J. HUIZINGA, Homo ludens, Madrid, Alianza/Emecé, [1954] 2000, p. 27; R. CAILLOIS, Man, play, and games, cit., pp. 6-7. 
En la medida en que se puede decidir jugar o no jugar, las normas constitucionales de una actividad lúdica regulan una actividad libre, voluntaria. Que se trate de una actividad libre guarda relación con el hecho de que el cumplimiento de las normas constitucionales no viene respaldado por ninguna norma de sanción. Unas reglas de juego formadas exclusivamente por normas constitucionales es un sistema normativo que no contempla la imposición de sanciones negativas en caso de que éstas sean incumplidas. Desde esta perspectiva, las normas constitucionales se definen como aquellas normas compartidas que, teóricamente, todos los miembros de una comunidad de agentes asumen como válidas mientras llevan a cabo la actividad definida. Suponer que todos los miembros asumen las normas de esa actividad como válidas significa que, en principio, cada uno de ellos acepta voluntariamente someterse a las reglas del juego, esto es, acepta adecuar su conducta a aquellas reglas comunes que constituyen la actividad en cuestión. Siendo esto así, el recurso a la coacción como medio para asegurar el cumplimiento de las normas no sólo no debería resultar necesario, sino superfluo e, incluso, contraproducente.

\subsection{Lo lúdico y lo cotidiano}

En su función descriptiva, las normas constitucionales de las reglas de los juegos construyen conjuntamente el mundo vinculado a la actividad regulada en ellas, mundo que adquiere autonomía respecto al mundo de la vida cotidiana. En primer lugar, literalmente dentro del mundo vinculado a la actividad de jugar no habría ningún ente más de los estrictamente necesarios, ni esos entes tendrían ninguna característica más de las estipuladas por las propias reglas del juego y que vienen determinadas por el objetivo del juego estipulado y los movimientos considerados correctos para la consecución del mismo. Así, lo que una palabra significa en el mundo vinculado a las reglas de un juego suele diferir sustancialmente del significado que se le atribuye en el mundo de la vida cotidiana porque también los objetivos y valores, y las acciones reguladas son sustancialmente distintas.

La separación entre el mundo generado por las reglas de un juego y el mundo de la vida cotidiana se evidencia a través de los diferentes valores y objetivos que dan cuenta de la actividad que tiene lugar en cada uno de ellos. Que el juego sea una diversión guarda relación con que el objetivo (lo que tiene valor) venga determinado por el propio juego, pues esto permite que el objetivo último fijado resulte trivial en la mayoría de juegos. Los objetivos de los juegos resultan triviales porque la determinación de ganadores y perdedores 
no tiene consecuencias que se alarguen más allá de la partida en concreto (una partida a un juego se desarrolla con total independencia respecto a cualquier otra partida), ni tampoco más allá del ámbito del propio juego, es decir, respecto a la consecución de otros objetivos o valores de otras actividades que sí repercuten sobre el proyecto de vida personal. Con todo, lo anterior requiere ser precisado, pues hay casos en que la actividad lúdica sí tiene repercusiones sobre la vida cotidiana: así, por ejemplo, en los juegos con un componente físico, cabe la posibilidad de lesionarse; otros supuestos serían el de los juegos con dinero (normalmente de azar), y también cuando se juega por dinero, es decir, cuando se hace de manera profesional. En estos casos, quien se arriesga a lesionarse, o juega con o por dinero debería aceptar las posibles consecuencias negativas que del jugar se puedan derivar para su vida cotidiana, circunscribiéndolas al ámbito del juego (v. gr., no demandando al causante de la lesión sufrida, siempre que ésta haya sido resultado de una acción circunscrita a la partida). Cuando el agente no separa la actividad lúdica de la vida ordinaria, el juego se pervierte ${ }^{8}$. Así pues, en la medida en que el objetivo viene dado, el juego supone una forma de evasión temporal de la responsabilidad de tener que tomar decisiones serias acerca de qué es valioso y cómo alcanzarlo. El hecho de que, para el jugador que está jugando, lo único que tiene valor es precisamente el objetivo que el juego le propone, implica que la preocupación por los objetivos serios de la vida queda en suspenso. Lo anterior permite distinguir, de momento, tres planos: 1 ) el plano de la vida cotidiana ${ }^{9}$ o de lo serio, esto es, el de la vida dirigida por objetivos y decisiones particulares; 2) el plano de evasión de la vida cotidiana o de lo lúdico (o lo no serio), en que el juego aparece como una distracción del deber y la responsabilidad de decidir; y 3) el plano de lo serio de lo lúdico, de la seriedad de los objetivos establecidos por el juego para el jugador, quien los adopta en exclusividad mientras está jugando ${ }^{10}$. Con base en esta división, los jugadores se caracterizarían por adoptar el objetivo del juego como lo único serio o con valor, distrayéndose temporalmente de su cotidianidad. En la medida en que se abandona al objetivo propuesto por el juego, "jugador" es aquel que deja, en cierto modo, de ser él mismo para devenir el agente construido por las reglas del juego ${ }^{11}$.

8 R. CAILLOIS, Man, play, and games, cit., pp. 5 y 43-55.

9 Una fenomenología de la vida de la vida cotidiana, en P. BERGER; T. LUCKMANN, La construcción social de la realidad, Buenos Aires; Madrid, Amorrortu-Murgua, 1968, pp. 36 ss.

10 J. HUIZINGA, Homo ludens, cit., pp. 17-18.

11 H.-G. GADAMER, “El juego como hilo conductor de la explicación ontológica”, en Verdad y método, $3^{\text {a }}$ ed., Salamanca, Ed. Sígueme, 1988, p. 155. 
Las reglas de los juegos incluyen también, por lo menos, una norma de secuenciación (o continuidad). Las normas de secuenciación establecen lo equivalente a la dimensión temporal del mundo construido por ellas. Respecto a éstas, Raz sostiene que «su propósito radicaría en que el juego siga adelante, o, más precisamente, esta norma determina parcialmente lo que cuenta como jugar el juego. El castigo por violar reiteradamente las normas de continuidad es que el infractor pierde el juego y es expulsado de él aunque podría haber castigos más pequeños por infracciones menores de las reglas de continuidad. Es el hecho de que la violación de una norma de mandato dé por resultado la pérdida del juego lo que indica que la norma es una norma de continuidad» ${ }^{12}$. La caracterización hecha por Raz de las normas de continuidad resulta, a mi entender, confusa. Primeramente, serían aquellas normas que establecerían el simple deber de mover por parte de un determinado jugador, pero además expresarían el deber de mover eligiendo la mejor opción posible para alcanzar el objetivo del juego (ganar la partida), o, lo que es lo mismo, mandarían permanecer jugando hasta el momento mismo en que se determina que se ha ganado la partida. Pero las consecuencias de la vulneración de esos dos deberes son bien distintas. En el primer caso, si un agente incumple el deber de mover cuando le toca, la consecuencia es que deja de jugar (la acción se considera inválida, nula, inexistente). En cambio, la vulneración del deber de actuar conforme a la mejor opción conlleva que el jugador pierda el juego. El juego finaliza igualmente, pero sólo para el jugador que no ha optimizado suficientemente sus movimientos. En ambos casos, las causas y consecuencias del cese del juego difieren sustancialmente. Se reserva la denominación de "normas de secuenciación" 13 (o "continuidad") para aquellas normas que establecen meramente el deber de mover, mientras que a las normas que fijan el deber de elegir la mejor de las opciones posibles para alcanzar el objetivo del juego las denominaré "normas de optimización". A diferencia de las normas de optimización, las normas de secuenciación vienen explicitadas en las reglas de juego. En tanto que enunciados descriptivos, este tipo de reglas establecen la temporalidad del mundo construido, esto es, ordenan la secuencia temporal de acontecimientos dentro del mundo construido por el juego.

12 J. RAZ, Razón práctica y normas, cit., pp. 133.

13 La denominación de "normas de secuenciación" se antoja más pertinente si se quiere prescindir del elemento volitivo del querer continuar jugando por parte de los agentes para focalizar la atención en la dimensión estrictamente normativa. 


\subsection{Estado de excepción en las actividades lúdicas}

Del carácter voluntario de las actividades lúdicas se deriva un rasgo fundamental de sus normas constitucionales: ningún reglamento de un juego recoge sanción alguna por abandonar el juego.

Reglamentariamente, no se estipula sanción negativa en caso de incumplimiento de una regla constitucional ${ }^{14}$, sino la nulidad de ese acto: se considera que esa acción no ha sucedido porque las reglas estipulan que es imposible (en un sentido ontológico) que suceda dentro de una partida. En tanto que el acto es considerado nulo o inválido por las reglas del juego, la conducta infractora sitúa al jugador fuera del juego: el individuo deja de jugar. Lo que se hace determina lo que se es, y lo que se hace y se es viene, a su vez, supeditado por la voluntad del agente de someterse a las reglas del juego.

Desde luego, cabe la posibilidad de que el resto de jugadores achaquen el incumplimiento de una regla del juego al desconocimiento de la regla (lo que presupone la creencia por su parte de que el agente tiene la intención de atenerse a ellas), o que lo acusen de hacer trampas (lo que presupone la creencia por su parte de que el agente conoce la regla vulnerada y de que ha actuado con la voluntad de incumplirla, pero con el fin de conseguir realizar el objetivo fijado por el juego $\left.{ }^{15}\right)$, o tal vez de aguafiestas o aburrido. En todos los casos, la actividad de

14 J.R. SEARLE, Actos de habla, $9^{a}$ ed., Madrid, Cátedra, [1969] 2017, p. 59.

15 R. CAILLOIS, Man, play, and games, pp. 7 y 45, señala que el hecho de que el tramposo pretenda sacar ventaja de las reglas, haciendo creer al resto de jugadores que las respeta cuando en realidad las está incumpliendo, es motivo suficiente para considerar que sí está jugando al mismo juego que el resto; arruina el juego sólo quien considera que éste no tiene sentido. Personalmente, discrepo de esta línea de pensamiento. No es suficiente para afirmar que se está jugando al mismo juego el que los jugadores compartan el objetivo fijado por el juego. Ello se pone de manifiesto en el hecho de que, en caso de que se pille al tramposo, la reacción normal sea la reprobación de su conducta e, incluso, su expulsión si ello supone una condición necesaria para continuar la partida, o, en caso de que no quepa subsanación del perjuicio, se invalide la partida y, por tanto, se finalice. Puede que el tramposo le encuentre sentido al juego, pero lo normal es que lo arruine para el resto de jugadores. Sólo si, una vez los demás jugadores se cercioran de que el tramposo está jugando con otras reglas y lo aceptan, entonces se puede afirmar que están llevando (e incluso, de que han llevado) a cabo la misma actividad, si bien el juego sea ahora otro distinto al que se suponía que estaban jugando inicialmente, pues las reglas han cambiado. Ad interim, el tramposo y el resto de jugadores aparentemente estaban realizando la misma actividad, cuando en realidad estarían realizando actividades distintas. Esa superposición de actividades también se presenta cuando los padres juegan con sus hijos pequeños y se dejan ganar. Aquí, los padres hacen trampas intencionadamente, sólo que para perder (enfocado desde las reglas del juego al que, aparentemente, se está jugando). A mi entender, en esa situación, los padres no han aceptado ni los valores del juego, ni las 
jugar queda suspendida momentáneamente hasta la aclaración de esa situación de excepcionalidad. En el caso de desconocimiento de la regla, lo normal es que se proceda a la explicación de la regla violada para luego exhortar a su acatamiento. En el caso de la acusación de hacer trampas, se cuestiona si el jugador que ha actuado desviadamente sigue jugando o no, suspendiéndose la actividad de jugar hasta que no se aclare ese punto. Con todo, la acusación de tramposo presupone que, al mismo tiempo, aún se considera que ese jugador está jugando, lo cual se espera que ponga de manifiesto mediante la rectificación de su movimiento antirreglamentario. Su movimiento se entiende como incorrecto por lo que se está a la espera de su rectificación. Si finalmente no rectificara su movimiento, entonces cabría la acusación de aguafiestas o aburrido por parte del resto ante la autoexclusión de esa persona. Aquí la acusación partiría de la toma de conciencia de que esa persona ha dejado de jugar. En los dos últimos casos, la acusación formulada supone una forma de sanción negativa (consistente en una reprobación verbal) que no viene estipulada en las reglas del juego, pero que es formulada por quienes continúan jugando, si bien la actividad se encuentra en suspenso; esas sanciones son, por expresarlo de alguna manera, externas a las reglas del juego, pero al mismo tiempo ejecutadas por parte de aquellos que continúan jugando, es decir, de aquellos que se hayan sometidos voluntariamente a ese orden normativo.

\subsection{Posición interna y posiciones intersticiales (interna y externa) en actividades libres}

De todo lo anterior se desprende que las desviaciones de la conducta se pueden enfocar desde dos perspectivas distintas, la del agente que decide desviarse y la de la comunidad de agentes. Parece evidente que, desde el primer punto de vista, la decisión de abandonar la actividad no supone sanción negativa alguna, puesto que sería el resultado de una decisión querida y voluntaria. Si se mira desde la óptica de la comunidad de agentes, entonces puede que ésta no reaccione negativamente; pero cabe también la posibilidad de que ésta sí reaccione negativamente. En el caso de la actividad de jugar, en ningún caso esa reacción negativa viene prevista reglamentariamente.

De manera más general, en las actividades voluntarias se pueden distinguir dos grandes posiciones: la interna y la intersticial. Se denominará "po-

reglas: aunque sus actividades resulten complementarias, en realidad, padres e hijos están llevando a cabo actividades distintas, con valores y reglas distintos. 
sición interna" a la de aquel agente que ha aceptado someterse a las normas constitucionales de una actividad y se halla inmerso en ella. Se denominará "posición intersticial" a la de aquel individuo que mantiene cierto tipo de relación con las normas constitucionales, pero de tal manera que no está situado ni propiamente dentro (no se somete a las reglas de juego), pero tampoco completamente fuera de la comunidad de agentes. Esta segunda posición, se puede subdividir en otras dos. Si esa situación de ambivalencia se debe a que, aún sin actuar como miembro de una comunidad de agentes, está decidiendo si formar parte o no de la comunidad (ya sea entrando o no entrando, o manteniéndose o saliéndose de ella), entonces se denominará "posición intersticial externa". Si, en cambio, se debe a que la comunidad de agentes, sin dejar la actividad, la suspende para demandar a un tercero que juegue, o para recriminarle que no lo haga, o para decidir expulsarlo de la partida (y, por tanto, de la comunidad de jugadores) en caso de que no quiera abandonarla (como podría ser el caso de un tramposo), entonces se denominará "posición intersticial interna".

A partir de esas dos posiciones, es posible también distinguir entre el "tiempo constituido" y el "tiempo constituyente" de una actividad instituida por un conjunto de normas constitucionales. El tiempo constituido transcurre mientras se aplican las normas de secuenciación y la actividad se desarrolla con normalidad por parte de la comunidad de agentes (cuando todos los considerados miembros de una comunidad se sitúan en una posición interna); el tiempo constituyente irrumpe cuando algún agente se sitúa en alguna de las dos posiciones intersticiales.

\section{ORDEN CONSTITUCIONAL COMO REGLAS DE LA CONVIVENCIA (O DEL JUEGO)}

\subsection{El carácter múltiple de las normas constitucionales de los orde- namientos jurídicos}

De manera análoga a las reglas de los juegos, los órdenes constitucionales definen y constituyen la actividad de comunidades políticas, estableciendo los valores y objetivos perseguidos, demarcando las acciones que se consideran válidas $y$, en ese sentido, posibles, así como las que se consideran inválidas (o nulas), y, en consecuencia, "imposibles". Respecto a la temporalidad de los órdenes constitucionales, me decanto por pensar que se 
caracterizaría por dos notas: su carácter cíclico (no lineal) y su vocación de permanencia indefinida en el tiempo; no se entrará en demasiados detalles, pero alguna cosa se comentará sobre esas particularidades. Un orden constitucional está compuesto por el conjunto de normas constitucionales de un ordenamiento jurídico.

En el ámbito de lo jurídico, se entiende por "normas definitorias constitucionales" aquellas que definen a la comunidad política y determinan la actividad de ésta. En otras palabras, son aquellas normas que construyen el mundo vinculado a la actividad de una comunidad política. En su función definitoria (o determinativa), esas normas crean una realidad normativa distinguible y separada de otras realidades, en particular de la realidad social ${ }^{16}$. Los componentes fundamentales que conforman el mundo de cualquier comunidad política son el territorio, la población, el propio Estado en tanto que organización política y un conjunto de valores y objetivos, junto a una serie de elementos simbólicos de carácter identitario ${ }^{17}$. El conjunto de valores y objetivos conformaría el proyecto político comunitario, a cuya realización, teóricamente, va encaminada la actividad de la comunidad. Al mismo tiempo, el proyecto político sería el rasgo identitario fundamental de las comunidades políticas, es decir, aquello que las definiría, aquello que determinaría lo que cada una de ellas es; en otras palabras, lo que una comunidad política es se identifica con lo que proyecta ser. En consecuencia, la realidad construida por las normas constitucionales no es sino una idealización, y la comunidad política una comunidad imaginada ${ }^{18}$ con vocación, eso sí, de transformar la realidad social, de modo que lo fáctico acabe correspondiéndose con el ideal.

16 Para una fundamentación, desde las neurociencias, de la acción humana como base del conocimiento humano y, en consecuencia, del carácter constructivo de la realidad, ver G. RIZOLLATI; G. SINIGAGLIA, Las neuronas espejo: Los mecanismos de la empatía emocional, Barcelona, Paidós, 2006; y G.M. EDELMAN; G. TONONI, El universo de la conciencia, Barcelona, Crítica, 2002. Una exposición sintética de las corrientes más importantes que han señalado el carácter constructivo de una realidad jurídica (relativamente) autónoma que se conforma a través del propio Derecho, en G. TEUBNER “How law thinks: toward a constructivist epistemology of law", Law E Society Review, vol. 23, núm. 5, 1989, pp. 727-758. Ver, también, P. BORDIEU, “Elementos para una sociología del campo jurídico”, en p. BOURDIEU; G. TEUBNER, La fuerza del Derecho, Santafé de Bogotá, Uniandes, 2000, pp. 155-220.

17 Definir la comunidad política vendría a corresponderse con lo que $\mathrm{K}$. LOEWENSTEIN, Teoría de la constitución, Barcelona, Ariel, 1964, pp. 63-65, denomina "la decisión política fundamental", concepto sobre el cual se articula la teoría de C. SCHMITT, La dictadura, $4^{\text {a }}$ ed., Madrid, Alianza ed., [1978] 2013.

18 A.-M. THIESSE, La creación de las identidades nacionales, Madrid, Ézaro, 2010; B. ANDERSON, Imagined communities, 2ª ed., Londres; Nueva York, Verso, 1991. 
En el ámbito de lo jurídico, se entiende por "normas constitutivas constitucionales" aquellas que articulan la comunidad alrededor de un proyecto político (de unos valores y objetivos) y constituyen la actividad de la comunidad política considerada al mismo tiempo como legítima y posible. Una "comunidad política" es aquel conjunto de individuos que comparten unas mismas reglas de juego constitucionales, esto es, que llevan a cabo una misma actividad política. Nuevamente, lo que debe ser (el ámbito de la acción política debida) y lo que es (el ámbito de la acción política factible) se confunden: delimitan el ámbito de la acción política considerada legítima por parte de la población y del Estado (esto es, la acción dirigida a la realización de los valores y objetivos comunitarios), ámbito que se corresponde con el marco de acciones consideradas posibles dentro del mundo construido por las normas definitorias constituyentes (lo cual determina lo que "es posible" o "no es posible" hacer, esto es, "lo que se puede" hacer en un sentido ontológico), de tal manera que la identidad comunitaria se identifica con el proyecto político supuestamente compartido ${ }^{19}$. Nótese que lo considerado "posible" o

19 R. SMEND, Constitución y derecho constitucional, Madrid, Centro de Estudios Constitucionales, [1928] 1985, sería, a mi entender, un buen exponente de una teoría constitucional que plantea las relaciones entre comunidad política y Estado en los términos aquí expuestos. A este respecto, define "Estado" como aquella asociación voluntaria real o soberana (pp. 52-62) en continuo proceso de integración en la realidad (pp. 62ss.). Más recientemente, P. HÄBERLE, Teoría de la constitución como ciencia de la cultura, Madrid, Tecnos, 2000. En España, una posición afín a la de Smend sería de la P. LUCAS, Teoría de la Constitución como ciencia cultural, $2^{\text {a }}$ ed., Madrid, Dykinson, 1998, y "Reflexiones en torno y dentro del concepto de Constitución: La Constitución como norma y como integración política", Revista de Estudios Políticos, n ${ }^{\circ}$ 83, 1994, pp. 9-28. Con todo, las diferencias con los planteamientos de Smend o Lucas son también importantes. De manera significativa, se rechaza la metodología fenomenológica sobre la cual articulan la idea, nuclear para sus teorías, de vivificación del espíritu (comunitario e individual). Así, mientras que estos autores atribuyen entidad ontológica (como vida espiritual) a la comunidad política, a mi entender, hay que entenderla como un constructo producto de convenciones, esto es, si se me permite el oxímoron, como una realidad ilusoria: si bien la conceptualización nos permite acceder a la realidad, al mismo tiempo supone hacer abstracción, alejarse de ella. Para un planteamiento teórico afín al que aquí se mantiene, ver S. FISH, "Force", en Doing what comes naturally, Oxford, ClaredonOxford University Press, 1989, pp. 503-524. Esa postura no sólo la considero más acertada epistemológicamente, sino también políticamente: frente a los peligros de posibles mistificaciones acríticas, considero saludable mantener una actitud reflexiva y crítica, sin negar por ello la necesidad y deseabilidad de generar sentimientos de pertenencia a una multiplicidad de comunidades. Por todo lo anterior, se cree más acertado metodológicamente la comparación político-normativa del orden constitucional con el orden de las reglas de los juegos. Otro tanto puede decirse de C. SCHMITT, Teoría de la constitución, Madrid, Alianza ed., 1982, sólo 
"imposible" de hacer lo es sólo visto desde dentro del mundo construido por las normas constitutivas constitucionales: la acción es "imposible" en el sentido de que quien actúa de manera contraria al orden constitucional se sale del mundo vinculado a éste y abandona la actividad comunitaria. En la medida en que el mundo construido por las normas definitorias constitucionales tiene su razón de ser en la actividad comunitaria establecida por las normas constitutivas constitucionales, éstas últimas resultan el tipo más importante dentro de las normas constitucionales.

La distinción que aquí se propone entre normas definitorias constitucionales y normas constitutivas constitucionales resulta análoga a la distinción entre definiciones legales y normas constitutivas (o que confieren poderes) ${ }^{20}$. Por un lado, las normas constitutivas se asemejan a las definiciones legales en que definen aquellos agentes a quienes se atribuyen potestades jurídicas: identifican quién tiene potestad para hacer qué y, en consecuencia, qué actos gozan de validez jurídica (en el sentido de haber sido realizados por quien tiene poder normativo para hacerlo). Pero, a diferencia de las definiciones legales, las normas constitutivas crean una actividad institucional, esto es, establecen que sólo quien tenga atribuida la capacidad para generar determinadas consecuencias jurídicas, las generará, siempre y cuando su conducta cumpla con lo establecido en las normas constitucionales ${ }^{21}$.

Las normas constitutivas constitucionales no consisten en normas prescriptivas $^{22}$. Su incumplimiento no comporta la imposición de una sanción,

que mientras Smend entiende que la unidad (el consenso) se alcanza mediante la integración de la diversidad, Schmitt considera que la unidad requiere uniformidad.

20 M. ATIENZA; J. RUIZ, Las piezas del Derecho, $4^{\mathrm{a}}$ ed., Madrid, Ariel, 2012, pp. 78-81; J. FERRER, Las normas de competencia, Madrid, CEPC, 2000; D. MENDOCA, Introducción al análisis normativo, Madrid, CEC, 1992.

21 Según M. ATIENZA; J. RUIZ, Las piezas del Derecho, cit., pp. 83-89, estructuralmente, la fórmula canónica de las normas que confieren poderes sería la siguiente: "Si se da el estado de cosas X y Z realiza la acción Y, entonces se produce el resultado institucional R."

22 "J.R. SEARLE (Actos de habla, pp. 50-60) es quien populariza la contraposición entre normas constitutivas y normas regulativas (o prescriptivas), contraposición que le da pie a otra entre hechos brutos y hechos institucionales. Los hechos institucionales serían aquellos creados por sistemas de normas constitutivas y que, en consecuencia, sólo se pueden explicar haciendo referencia a este tipo de normas (p. 68-72). Por el contrario, J. RAZ, Razón práctica y normas, cit., pp. 124-128, sostiene que ambas categorías son indistinguibles, pues toda norma sería regulativa y constitutiva al mismo tiempo. D. GONZÁLEZ, "Clasificar acciones. Sobre la crítica de Raz a las reglas constitutivas de Searle”, Doxa, núm. 13, 1993, p. 265-276, por un lado, admite la crítica de Raz de que toda norma es regulativa y constitutiva simultáneamente. Con todo, considera que esa distinción entre normas resulta pertinente. En el caso de las normas 
sino la invalidez o nulidad del acto $^{23}$. Por otro lado, un acto llevado a cabo por quien tiene la capacidad normativa se considera, en principio, válido, aunque sin menoscabo de que pueda ser invalidado en caso de que no se cumplan determinados requisitos formales y materiales.

No se debe confundir el orden constitucional con el ordenamiento jurídico: el orden constitucional se refiere sólo a aquellas normas que definen y constituyen una comunidad política. Por otro lado, las normas constitucionales no se pueden identificar sin más con los artículos de rango constitucional: ni todo artículo recogido en una constitución consiste necesariamente en una norma constitucional del ordenamiento jurídico en el sentido aquí expuesto, ni todas las normas constitucionales de un ordenamiento jurídico tienen porqué venir recogidas en el texto constitucional. No todo artículo constitucional es necesariamente una norma constitucional por dos razones. En primer lugar, porque no todos los artículos constitucionales definen a la comunidad política, es decir, no alcanzan la dimensión holística que caracteriza este tipo de normas ${ }^{24}$. En segundo lugar, porque puede que haya normas de rango in-

constitutivas, la descripción de la conducta resulta imposible si la norma no existe, pues es la norma la que crea la conducta (la conducta es institucional y, por tanto, la descripción sería siempre interpretativa), mientras que, en el caso de las normas regulativas, estas regularían y constituirían conductas naturales susceptibles de ser descritas como hechos naturales no interpretados (hechos naturales brutos) o interpretados, o como hechos institucionales (interpretados a partir de la propia norma). Su postura se sostiene sobre la distinción de González entre descripciones no interpretativas (hechos naturales brutos) o descripciones interpretativas (ya sea de hechos naturales o institucionales) y la afirmación de la posibilidad del primer tipo de descripciones. Personalmente, discrepo. A mi entender, si un hecho es plenamente bruto, es decir, se presenta como un hecho objetivo, puro, entonces no se puede enunciar nada de éste. González tiene razón cuando afirma que resulta imposible decir "yo prometo" si no existe la regla de prometer; pero, entonces, de manera similar es imposible describir el hecho de "dar 50 libras esterlinas" si no se dispone de la noción de dar, de 50 y/o de libra esterlina. Esa presunción remite, a mi entender, a un empirismo muy simple e ingenuo ya superado. Más acertadas me parecen las propuestas de A. PLACANI, "Constitutive and regulative rules: a dispute and a resolution", Phenomenology and Mind, núm. 13, 2017, pp. 56-62, y de M. ATIENZA; J. RUIZ, Las piezas del Derecho, cit., pp. 69 ss, las cuales sitúan la distinción en el tipo de conducta regulada: mientras que las normas regulativas mandan o permiten, las normas constitutivas (no puras) confieren poderes.

23 La diferencia entre nulidad y sanción resulta significativa, pues la nulidad de un acto o una norma supone tratarlos como si nunca hubieran existido (porque su existencia no se considera posible en el mundo creado por el ordenamiento jurídico), mientras que la imposición de una sanción implica la comisión de un acto ilícito, pero, por ello mismo, considerado posible.

24 Respecto al orden constitucional español, a esta idea responde la distinción de E. GARCÍA DE ENTERRÍA, La Constitución como norma y el Tribunal Constitucional, $3^{\mathrm{a}}$ ed., Madrid,

ISSN: 1133-0937

DOI: https://doi.org/10.20318/dyl.2021.6107
DERECHOS Y LIBERTADES

Número 45, Época II, junio 2021, pp. 233-266 
fraconstitucional que se tengan por normas constitucionales ${ }^{25}$. En resumen, la condición de norma constitucional no depende de su rango jurídico, si no de su aceptación como norma definitoria de la comunidad política. Afirmar que el carácter de norma constitucional depende de la aceptación social equivale a afirmar que depende de un hecho fáctico extrajurídico. Este planteamiento resulta afín a la caracterización de la regla de reconocimiento hartiana ${ }^{26}$.

Hechas las precisiones anteriores, en lo que sigue se hablará indistintamente de orden constitucional, normas constitucionales o de constitución (constituciones, textos constitucionales, etc.). A mi entender, una buena razón para justificar esa equiparación, y ello pesar de su imprecisión, residiría en que la mayoría de normas constitucionales suelen estar ubicadas en el texto constitucional, lo cual se debe a que una de las funciones atribuidas a las constituciones reside precisamente en constituir la comunidad política.

Es precisamente esa caracterización de las constituciones como los textos en los cuales se establecen las reglas de juego, o normas de convivencia, de las comunidades políticas ${ }^{27}$ la que anima este trabajo. Así entendidas, las constituciones se tienen por la expresión del consenso fundamental pretendidamente existente en una comunidad o, lo que viene a ser lo mismo, por los textos jurídicos en que se define y constituye una comunidad política.

Una última aclaración antes de continuar. El sentido en el que se entiende aquí "norma constitucional" es puramente formal, esto es, como aquella norma que, por su fundamentalidad, ocupa una posición jerárquicamente superior respecto a otro tipo de normas que integran un ordenamiento jurídico, e indistintamente de cuales sean los valores y principios en ella expre-

Civitas, 1983, pp. 97-99, entre valores constitucionales básicos y fundamentantes y el resto de principios constitucionales menos relevantes. Otros autores que también establecen esa jerarquía dentro de los textos constitucionales. Ver, por ejemplo, G. PECES-BARBA, Los valores superiores, Madrid, Tecnos, 1984, pp. 38-41, o F.J. LAPORTA, “Norma básica, Constitución y decisión por mayorías", en LAPORTA, F.J. (ed.), Constitución: problemas filosóficos, CEPC, 2003, pp. 75-92.

${ }_{25}$ Para el caso español, el sentido de los artículos en que se establecen los criterios recogidos en el Código Civil (ver Título I del Libro Primero) para determinar quien posee la nacionalidad española (algunos dirían: quien "es" español) serían buenos candidatos para este segundo supuesto.

26 H.L.A. HART, El concepto de Derecho, $3^{\mathrm{a}}$ ed., Buenos Aires, Abeledo Perrot, [1961] 1998 , pp. 125 ss.

27 A modo ilustrativo, ver, para el caso de la actual constitución española, G. PECESBARBA, “Un consenso para la convivencia”, El País, 6-12-1981, y "La Constitución como reglas del juego", El País, 6-12-1977, o E. GARCÍA DE ENTERRÍA, La Constitución española de 1978 como pacto social y como norma jurídica, Madrid, INAP, 2003, pp. 31 ss. 
sados, es decir, de cuál sea su contenido material ("sentido sustantivo" de la norma) ${ }^{28}$. Así, por ejemplo, tanto la constitución española de 1978, como las leyes fundamentales del régimen franquista cabe entenderlas como normas constitucionales en un sentido formal.

\subsection{Obligatoriedad de los ordenamientos jurídicos y legitimación del poder político}

Como se ha comentado, la actividad de jugar es una actividad libre, de manera que, ulteriormente, el jugar dependía de que los participantes aceptasen cumplir voluntariamente con las reglas del juego. Esa característica no se veía afectada por la posibilidad de que, desde quienes se encontraban en una posición intersticial interna (esto es, desde quienes querían jugar), reaccionaran negativamente ante la negativa a jugar por parte de un individuo a quien consideraban miembro de la comunidad de jugadores: el hecho de actuar obligado resultaba, por definición, incompatible con el carácter lúdico de la actividad de jugar. Por las características propias de la actividad de jugar, se podría decir que la validez y, por tanto, la obligatoriedad de las reglas del juego no es separable de su legitimidad.

No sucede lo mismo en el caso de las normas constitucionales de los ordenamientos jurídicos. Como regla general, la obligación jurídica se asegura mediante el uso de la violencia contra aquellos que no aceptan un determinado orden constitucional (lo que les ubica en una posición intersticial externa) por parte de quienes sí se adhieren al mismo (situándose en una posición intersticial interna $)^{29}$, como suele ser el caso de las diferentes instituciones del Estado respecto al orden constitucional que éste mismo ha creado. A diferencia de la actividad de jugar, cuya continuidad exige el consenso unánime de la comunidad de jugadores, la continuidad del orden constitucional es compatible con la existencia de disidentes dentro de la comunidad política; de hecho, lo

28 La distinción entre el sentido formal y el material de las normas constitucionales tiene su correlato en la distinción entre el sentido formal y el material (o sustantivo) de las constituciones. Ver M. ATIENZA, “Constitución y argumentación”, Anuario de Filosofía del Derecho, 2007, pp. 199.

${ }_{29}$ Para algunas interesantes reflexiones en torno al componente místico de la autoridad $\mathrm{o}$, en otras palabras, de las relaciones entre fuerza y justicia en el momento constituyente, ver J. DERRIDA, "Del derecho a la justicia", en Fuerza de ley, Madrid, Tecnos, 2008, pp. 52-54, donde aborda la aporía de la aceptación del sometimiento a ley como pretendido fundamento justificador del ordenamiento jurídico en los estados de derecho. 
extraño sería que no los hubiera. En conclusión, la aceptación social de un orden jurídico no es condición necesaria para su existencia: su eficacia determina su existencia, no la valoración moral que hagan una serie de individuos. La validez y la obligatoriedad jurídicas de las normas constitucionales resultan independentes de la voluntad de quienes se hallan sujetos a ellas ${ }^{30}$.

30 Enfocado desde la filosofía del derecho, la separación de validez y legitimidad va de la mano con la tesis iuspositivista de la separación de derecho y moral, aquí defendida. Valga como ejemplificación de la amplísima literatura en torno a las (des)conexiones entre derecho y moral, el debate entre el iuspositivista R. GUASTINI ("Derecho dúctil, derecho incierto", Anuario de Filosofía del Derecho, vol. XIII, 1996, pp. 111-123) y el postpositivista G. ZAGREBELSKY, El derecho dúctil, Madrid, Trotta, 1995). Enfocado desde la teoría constitucional, y dentro del constitucionalismo, este mismo debate encuentra una ramificación en el binomio deberes fundamentales (que resalta la cuestión de la validez y obligatoriedad de la Constitución) y derechos fundamentales (como fuente de legitimidad). Tradicionalmente, se ha entendido que la función normativa de la Constitución reside en organizar y limitar la acción política del Estado: de ahí que se haya enfatizado su carácter vinculante para los poderes públicos, lo que ha derivado en la escasa atención prestada por la doctrina a los denominados "deberes fundamentales" de la ciudadanía. A ello ha contribuido también el que las propias constituciones no establezcan normas de sanción que acompañen tales deberes (criterio éste que, de hecho, se utiliza para distinguir entre "deber" y “obligación"), relegando este asunto a su posterior desarrollo legislativo. Este planteamiento expresaría la versión contemporánea de la analogía entre la actividad de jugar y la actividad política encaminada a constituir un determinado orden constitucional que, con miras a su legitimación, presenta el sometimiento a dicho orden como dependiente de una decisión voluntaria (esto es, como una decisión personal que no viene respaldada por ninguna norma de sanción). En consecuencia, y sin poner en cuestión la vinculatoriedad jurídica de las constituciones en la actualidad (ver E. GARCIA DE ENTERRÍA, La Constitución como norma y el Tribunal Constitucional, cit., 1983), cuando aquí se afirma que las normas constitucionales son de obligado cumplimiento para quienes la propia constitución considera miembros de la comunidad política (la ciudadanía), se está pensando concretamente en la obligación que se deriva de la posibilidad de que el Estado recurra a la violencia bajo la lógica del estado de excepción, esto es, en aquellas situaciones en que se considera amenazado el orden constitucional como tal, cuestión ésta que será abordada en breve. Sobre el debate acerca del contenido, el alcance de esos deberes fundamentales y los peligros que encierran para la articulación del Estado como un Estado de Derecho ante una posible interpretación extensiva que vuelva exigible una militancia activa respecto a determinadas ideas políticas, ver S. VARELA "La idea de deber constitucional”, Revista Española de Derecho Constitucional, núm. 4, 1982, pp. 69-96. Sobre la noción de "deber constitucional", ver también, J.M. GOIG, "La constitucionalización de deberes", Revista de Derecho de la UNED, núm. 9, 2011, pp. 111-148; F. LANCHESTER, "Los deberes constitucionales en el derecho comparado", Revista de Derecho Constitucional Europeo, núm. 13, 2010, pp. 67-81; M.A. ALEGRE, “Los deberes en la constitución española: esencialidad y problemática", Teoría y realidad constitucional, núm. 23, 2009, pp. 271-291; F. RUBIO, "Los deberes constitucionales", Revista Española de Derecho Constitucional, núm. 62, 2001, pp. 11-56; G. PECES-BARBA, "Los deberes fundamentales", Doxa, núm. 4, 1987, pp. 329-341. 
Con todo, toda organización estatal, incluso las más autoritarias, actúan con miras a obtener el mayor grado de aceptación social posible del orden constitucional creado por ellas. A mi entender, una razón importante que explica esa pretensión reside en que el sometimiento voluntario facilita asegurar la pervivencia del orden constitucional, esto es, su perpetuación en el tiempo. Que el Estado logre generar un deber jurídico de obediencia al orden constitucional por el hecho de que dispone de la capacidad para imponerse mediante la fuerza física no genera ningún tipo de deber moral: en la medida en que lo valoren como injusto, cabe esperar el rechazo de ese orden, así como un deber moral de desobediencia al mismo. De esta forma, se produce una relación tensa entre lo específico del Estado, a saber, la autoatribución del ejercicio monopólico legítimo de la violencia ${ }^{31}$, y la legitimación de ese poder político-constitucional por parte de la población, lo cual pasa por su aceptación voluntaria (sean cuales sean las razones de tal aceptación). Así, cuanto mayor sea el grado de aceptación social del orden constitucional, mayor la obediencia voluntaria del orden jurídico y, por tanto, mayores también las probabilidades de continuidad del orden constitucional mediante un empleo menor de recursos para su imposición mediante la fuerza física. A su vez, la legitimidad de un orden constitucional y las razones éticas para la obediencia al derecho pasan por presentarlo como un orden que articula las relaciones del Estado con quienes considera miembros de la comunidad política como relaciones de convivencia ${ }^{32}$. E inversamente, cuando la obediencia al orden constitucional se impone mediante la violencia, más improbable resulta que el violentado pueda concebir ese orden constitucional como un orden que constituye relaciones basadas en la convivencia social y política y, por ende, más improbable resulta que acepte voluntariamente someterse al orden constitucional.

\subsection{Lo sagrado y lo cotidiano}

Si las reglas de los juegos crean un mundo vinculado a la actividad lúdica regulada, el cual goza de autonomía respecto al mundo de la vida cotidiana, los órdenes constitucionales también construyen un mundo, sólo que éste tradicionalmente se ha situado en el ámbito de lo sagrado. En lo que si-

31 M. WEBER, “La política como vocación”, El político y el científico, $2^{\mathrm{a}}$ ed., Madrid, Alianza ed., 1998, pp. 83-84.

32 G. PECES-BARBA, Los valores superiores, cit., pp. 45 y 73-74. 
gue, se expone esa visión tradicional del derecho que vincula el orden constitucional con el ámbito de lo sagrado.

Se entiende por "sagrado" el sentido que Agamben le da a ese término, quien vincula la noción de homo sacer (o "nuda vida") a la de poder soberano ${ }^{33}$. De esta forma, lo sagrado encuentra su ámbito en el tiempo constituyente del orden político, lo cual resulta equiparable, visto desde un punto de vista intersticial interno, al momento constituyente del orden del mundo. Desde esta perspectiva, el mundo construido por el orden constitucional se presenta como una realidad objetiva, si bien ideal, en otras palabras, como un orden justo proyectado susceptible de desmoronarse o de ser demolido. La existencia del disidente pone en evidencia la posibilidad de otras realidades alternativas al mundo ordenado por la constitución, realidades que son concebidas como estados caóticos, informes, anárquicos. Así pues, siempre desde el punto de vista de un miembro situado en una posición intersticial interna, el orden constitucional requiere para su realización de la acción proactiva de la comunidad para que esa realidad no degenere en una situación de desorden.

La ubicación de las normas constitucionales en el mundo de lo sagrado haya su contrapunto en el mundo de la cotidianidad (o de lo profano, si se prefiere). Mientras que el ámbito de lo sagrado guarda relación, siempre desde una posición intersticial interna, con la realización de aquellos fines más trascendentes relacionados con el interés general de la comunidad, el ámbito de lo cotidiano está conformado por la concurrencia de intereses particulares. Con todo, esos ámbitos estarían conectados entre sí: en un estado de normalidad, la regulación normativa de lo cotidiano persigue, supuestamente, articular la multiplicidad de intereses individuales con miras a la realización del bien común. En este punto se ponen también de manifiesto algunas diferencias entre las reglas de los juegos y los órdenes constitucionales: 1) las reglas de los juegos establecían objetivos y valores triviales, los órdenes constitucionales no; 2) las reglas de los juegos no regulan ninguna actividad cotidiana guiada por la seriedad de objetivos e intereses particulares, los órdenes constitucionales se despliegan en ordenamientos jurídicos que, potencialmente, abarcan toda actividad cotidiana.

Desde una posición interna, las normas constitucionales definen e identifican las comunidades políticas ${ }^{34}$; describen un orden que se tiene por constituido, que tiene una forma dada, y establecen quién puede (en el sentido de posibilidad

33 G. AGAMBEN, Homo sacer I: El poder soberano y la nuda vida, Valencia, Pre-Textos, 1998.

34 J.J. GOMES, Teoría de la Constitución, Madrid, Dykinson, 2004, pp. 104-105. 
ontológica) hacer qué. Desde esta perspectiva interna, la comunidad política se presenta como una realidad objetiva, evidente e incuestionada, y cuya existencia y posibilidades de acción no dependen de la voluntad de sus miembros. En otras palabras, en una situación de normalidad, las normas constitucionales son aquellas cuya transgresión ni se plantea como posible por parte de los miembros de la comunidad, pues supondría lo mismo que contravenir las leyes "naturales" del mundo en el que se desenvuelve su existencia cotidiana.

Por contraposición, desde una posición intersticial externa, los valores y normas constitucionales se conciben como la expresión de un programa político o ideológico transformador y configurador de la realidad social. Desde esta perspectiva, las normas constitucionales componen el proyecto político de una determinada comunidad: prescriben cómo debería estar configurado el orden social, cómo debería ser el mundo de la comunidad política. Se trata de un mundo construido, pues la manera cómo se define ese mundo responde a un proyecto transformador de esa misma realidad que es el objeto de la definición. Ese mundo idealizado es imposible que se corresponda completamente con el mundo presente, pues el mundo presente se caracteriza por la heterogeneidad de lo concreto, mientras que ese mundo idealizado presenta la comunidad como una abstracción homogénea. Esa distorsión respecto a los hechos se evidencia en la pretensión de unanimidad en la aceptación social de las reglas constitucionales por aquellos que, considerándose miembros de la comunidad, se sitúan en una posición intersticial interna ${ }^{35}$. La comunidad política se presenta como una entidad imaginada, ilusoria, como una idealización que no encuentra correspondencia en lo empírico, como un constructo que es ideado $\mathrm{y}$, en consecuencia, susceptible de ser manipulado ${ }^{36}$.

35 Conviene advertir que es precisamente cuando se explicitan los discursos acerca de la existencia de un consenso constitucional y unas reglas del juego compartidas, es decir, en situaciones en que tal consenso no se da. Lo que se tiene por obvio no debería explicitarse, si realmente lo fuera. Esas apelaciones a las reglas de juego compartidas se pueden mover entre una sincera voluntad de encuentro con el otro y el mantenimiento de un status quo privilegiado configurado por las reglas actuales. Para un análisis de estos dobleces en la época de la transición española, ver R. DEL ÁGUILA “La transición a la democracia en España: reforma, ruptura y consenso". Revista de Estudios Políticos, núm. 25, 1982, pp. 101-127. Un documento que ejemplifica los esfuerzos "pedagógicos" por afirmar, conformar y consolidar un consenso durante esa época en "Las reglas del juego: el compromiso de la libertad", http://www.rtve.es/ alacarta/videos/archivo-constitucion/reglas-del-juego-compromiso-libertad/1596263/.

36 J. ÁLVAREZ, "Lo sagrado y lo profano en la nación. Cultura, identidad y movilización", en Historia y Filosofía politica, jurídica y social. Estudios en homenaje al profesor Gregorio Peces-Barba, Madrid, Dykinson, 2008, vol. IV, pp. 42. 
Para los miembros de la comunidad, el carácter ilusorio, idealizado del mundo construido por las normas definitorias constitucionales no conlleva que ese mundo se comprenda como falso o ficticio. Bien al contrario, ese mundo idealizado se tiene por el verdadero o real ${ }^{37}$. En primer lugar, el mundo idealizado se tiene como el real, pues esa idealización se considera el resultado de la discriminación de aquellos rasgos considerados relevantes para la conformación de la propia identidad como miembro de la comunidad política. Desde esta visión, la vida cotidiana, la que se desenvuelve en el mundo presente entre individuos particulares y está guiada por intereses personales diversos, se articula sobre ese mundo idealizado. En segundo lugar, en la medida en que los juicios de verdad sólo se pueden enunciar respecto a entidades cuya forma está determinada, esto es, que requieren de leyes que estén operativas y generen un orden, cada colectivo concibe el mundo construido por las normas constitucionales de la comunidad a la que se adscriben como el auténticamente real, pues fuera de ese orden sólo se concibe el caos, lo informe, la anarquía (literalmente, la ausencia de todo principio ordenador ${ }^{38}$. De esa forma, a la norma constitucional se le confie-

37 Para un estudio de la mentalidad religiosa, ver J. AMADOR “Mito, símbolo y arquetipo en los procesos de formación de la identidad colectiva e individual", Revista mexicana de ciencias políticas y sociales, vol. 44, núm. 176, 1999, pp. 61-99, y M. ELÍADE, Lo sagrado y lo profano, $4^{\mathrm{a}}$ ed., Madrid, Guadarrama/Punto Omega, 1981. R. GUASTINI, “Teoría de las reglas constitutivas: Searle, Ross, Carcaterra", en A. SQUELLA (ed.), Alf Ross: Estudios en su homenaje, Valparaíso, Universidad de Valparaíso, 1984, pp. 306, critica la apelación a normas constitutivas, pues generan una "atmósfera metafísica", un mundo mágicamente duplicado a través del lenguaje. Sostener que los ordenamientos jurídicos crean una "atmósfera metafísica" y que, por lo tanto, si se quiere comprender qué es el Derecho ese rasgo tiene que ser explicado, no es lo mismo que afirmar que esa atmósfera se corresponda con una realidad metafísica. En la medida en que los seres humanos carecemos de intuición intelectual y que nuestro conocimiento de la realidad externa e interna se sustenta sobre procesos neuronales, inevitablemente construimos un mundo que no se corresponde con la realidad; en la medida en que se utilicen conceptos para explicar la realidad, el modo de conocer humano supone una idealización. Así pues, nuestras creencias son reales en el sentido de que creer algo es un hecho (por falsa que sea esa creencia), y resultan explicativas de la realidad en tanto en cuanto actuamos condicionados por nuestras creencias.

38 Sin menoscabo de sus diferencias, Huizinga y Caillois comparten dos tesis: la primera, que el juego es inspirador de comunidad; y segunda, que la cultura es juego en la medida en que el juego impulsa hacia la superación de los puros condicionamientos naturales. Si el juego conlleva la creación de un espacio-tiempo distanciado de la cotidianidad, la cultura genera mundos de ideas distanciados de lo estrictamente natural o biológico. Esa capacidad de ideación posibilita la distinción de lo sagrado frente a lo profano y también, por ejemplo, de la esfera de lo jurídico como ámbito (total o relativamente) autónomo frente a otras dimen- 
ren las notas características de lo sagrado en tanto en cuanto constituirían una realidad trascendente que ordena el mundo de lo profano, de la vida cotidiana de las personas movidas por objetivos e intereses particulares ${ }^{39}$. Esto vale para toda organización política, desde las de la antigüedad que fundamentan el poder político en relatos mitológicos fundacionales ${ }^{40}$ hasta los regímenes absolutistas modernos ${ }^{41}$, y también para las comunidades políticas contemporáneas secularizadas ${ }^{42}$.

Si bien las constituciones se aprueban en momentos históricos determinados, estas se encuentran sujetas a su permanente reactualización, tanto a través de la actividad legislativa en la que se despliega ese proyecto político, como de la actividad política del parlamento, la actividad jurisprudencial del poder judicial o la doctrina de los tribunales constitucionales; es decir, la ordenación de la vida cotidiana por parte del Estado incide en la interpretación del orden constitucional y, por consiguiente, en la identidad comunitaria $^{43}$. Esta constante actividad (re)interpretadora del orden consti-

siones. Para una exposición de las convergencias y divergencias entre estos dos autores, ver C. MORILLAS, "Huizinga-Caillois: variaciones sobre una visión antropológica del juego", Enrahonar, núm.16, 1990, pp. 11-39.

39 En esa línea, ver P. LUCAS, Teoría de la Constitución como ciencia cultural, cit., pp. 92104. A modo de ejemplo, sobre la concepción de la constitución estadounidense como texto sagrado de una religión civil, ver J.M. BALKIN, Constitutional redemption, Harvard, Harvard University Press, 2011; y S. LEVINSON, Constitutional faith, Princeton, Princeton University Press, 1988.

40 M. ELÍADE, Lo sagrado y lo profano, cit.

41 J.F. SEGOVIA, "La monarquía parlamentaria. Orígenes y causas de la desnaturalización de la monarquía”, Verbo, núm. 535-536, 2015, pp. 425-447; J.G. MARÍN “La doctrina de la soberanía del monarca (1250-1700)", Fundamentos: cuadernos monográficos de teoría del estado, derecho público e historia constitucional, núm. 1, 1998, pp. 63 ss., quien señala la plenitudo potestatis del Derecho canónico medieval como precedente directo de la noción de "soberanía" en su sentido moderno.

42 E. GENTILE, Politics as religion, Princeton, Princeton University Press, 2006; y J. ÁLVAREZ, “Lo sagrado y lo profano en la nación. Cultura, identidad y movilización”, cit. Para el caso de Alemania, pero exportable a la tradición occidental, ver G. L. MOSSE, La nacionalización de las masas, Madrid, Marcial Pons, [1975] 2005. Sobre las dinámicas mistificadoras, totalizadoras del Estado contemporáneo desde dos paradigmas contrapuestos, ver M. HORKHEIMER y T. ADORNO, Dialéctica de la Ilustración, 2a ed., Madrid, Trotta, [1969] 1997, pp. 59 ss); y E. VOEGELIN, “Las religiones políticas”, en Las religiones políticas. Madrid, Trotta, [1938] 2014, pp. 27-71.

43 E. RENAN, ¿Qué es una nación?, $2^{\mathrm{a}}$ ed., Madrid, Centro de Estudios Constitucionales, [1882] 1983, expresa esta idea en su cita clásica: “La existencia de una nación es (perdonadme esta metáfora) un plebiscito cotidiano, como la existencia del individuo es una afirmación per-

ISSN: 1133-0937

DOI: https://doi.org/10.20318/dyl.2021.6107
DERECHOS Y LIBERTADES

Número 45, Época II, junio 2021, pp. 233-266 
tucional por parte del Estado puede generar tanto el fortalecimiento, como el debilitamiento del consenso constitucional ${ }^{44}$, de manera que haya colectivos que dejen de sentirse identificados con la deriva político-identitaria del orden constitucional. Un aumento de la desafección social puede poner en riesgo la estabilidad del orden constitucional, pues, igual que el mundo construido por las reglas de un juego se mantiene en la medida en que hay jugadores que se guían por esas reglas, es decir, que continúen jugando, de forma paralela la existencia del mundo construido por un orden constitucional es difícilmente sostenible en el tiempo, si no hay una comunidad dispuesta a obedecer voluntariamente. Expresado aún de otra manera, las normas constitutivas constitucionales constituyen los poderes del Estado ordenadores de la comunidad política sólo en tanto en cuanto gozan de una eficacia generalizada duradera ${ }^{45}$, duración que requiere, por lo menos en el largo plazo, de un colectivo de individuos que actúen conforme a las reglas del juego comunitario de forma que esas normas sean practicadas voluntaria y duraderamente en el tiempo.

La eficacia del orden constitucional se puede obtener mediante la obediencia voluntaria, o mediante el uso de la violencia.

Por la primera vía, la eficacia duradera del orden constitucional depende de la renovación constante de la aceptación de esas reglas de juego constitucionales por parte de un colectivo significativo de practicantes, quienes, de esa forma, continúan llevando a cabo la actividad regulada. De esta forma, el proceso constituyente permanente al cual se hayan sujetas las comunidades políticas requiere, a su vez, de la constante renovación de la aceptación social de un orden constitucional en constante transformación (mediante liturgias, ceremonias, festividades, etc.), o de espacios políticos "sagrados" (como serían las sedes parlamentarias para los sistemas parlamentarios o los palacios reales para los monárquicos), así como la adhesión a una serie de símbolos identitarios (jefe del Estado como símbolo de unidad, banderas, himnos, heroificación

petua de vida". Ver también R. SMEND, Constitución y derecho constitucional, pp. 63 y 136-137) y, más recientemente, G. ZAGREBELSKY, Historia y Constitución, 2a ed., Madrid, Trotta, 2011.

${ }_{44}$ A partir de las diferentes posibles relaciones entre el derecho producido por los Estados democráticos y de derecho y su recepción por la sociedad, K. LOEWENSTEIN, Teoría de la constitución, pp. 216-222, distingue entre constituciones normativas (acoplamiento constitución-sociedad), nominales (no integración de la Constitución en la vida política y social por defectos en la sociedad receptora) y semánticas (apropiación de la Constitución para beneficio propio por quienes detentan el poder del Estado).

45 H. KELSEN, Teoría pura del Derecho, $16^{a}$ ed., México, Porrúa, 2009, p. 57-63.

DERECHOS Y LIBERTADES

Número 45, Época II, junio 2021, pp. 233-266
ISSN: 1133-0937

DOI: https://doi.org/10.20318/dyl.2021.6107 
de personajes, mistificación de episodios históricos, etc.) ${ }^{46}$ serían las formas explícitas habituales institucionalizadas por el propio orden constituido dirigidas a asegurar su continuidad. Un ejemplo destacable se encuentra en la mitificación de los referéndums constitucionales, allí donde éstos se han celebrado, en tanto que explicitación del pretendido consenso social, y su reiteración festiva anual como modo de renovación cíclica del momento constitutivo de la comunidad $^{47}$.

En la medida en que las normas constitucionales tienen vocación de renovar el mundo constitucional mediante la participación activa de los miembros de la comunidad, se asemejan a las normas de continuidad (o secuenciación) discutidas en el apartado dedicado a las reglas de los juegos. Con todo, los juegos y los órdenes político-constitucionales se distinguen en lo siguiente: en los juegos hay un momento final resolutivo en que se determina el (los) ganador(es). En cambio, el objetivo de la actividad constitucional reside en que el juego continúe, esto es, en asegurar la continuidad misma de la comunidad política; gana quien consigue imponer y mantener su visión de orden constitucional.

\subsection{Violación del orden constitucional y estado de excepción}

Se sientan las bases para la existencia de un conflicto de carácter constituyente cuando dos colectivos consideran relevantes para la determinación de su identidad rasgos distintos que generan mundos idealizados que resultan incompatibles entre sí, o, expresado de otra manera, cuando una parte significativa de la población no acepta las reglas de juego constitucionales.

Como se acaba de comentar, ante un conflicto de carácter constituyente caben, básicamente, dos posibles respuestas: promover por vías pacíficas una mayor aceptación de las reglas de juego constitucionales; o bien imponer tales reglas mediante el recurso a la violencia ${ }^{48}$. En lo que sigue, me cen-

46 G.L. MOSSE, La nacionalización de las masas, cit., [1975] 2005; R. SMEND, Constitución y derecho constitucional, cit., pp. 96-97.

47 Frente a la irreversibilidad o linealidad del mundo ordinario, C. MORILLAS, "Huizinga-Caillois: variaciones sobre una visión antropológica del juego", cit., pp. 38-39, caracteriza la reversibilidad o circularidad temporal como la temporalidad propia del juego ("Sólo hay juego, soberanamente, si se juega-para-volver-a-jugar, si es posible recuperar su principio siempre. El juego es eterno o no es." (p. 38)). De manera similar a los juegos, y en contraposición con la legislación ordinaria, el orden constitucional se caracterizaría también por su circularidad temporal.

48 En contra de la posición de C. SCHMITT, El concepto de lo político, Madrid, Alianza ed., [1932] 1998, la relativa uniformidad sobre la cual se asienta el orden constitucional no

ISSN: 1133-0937

DOI: https://doi.org/10.20318/dyl.2021.6107
DERECHOS Y LIBERTADES

Número 45, Época II, junio 2021, pp. 233-266 
tro exclusivamente en esa segunda vía, la violenta, y sus consecuencias para comprender el orden constitucional como marco para la convivencia política y social.

La vía de la imposición mediante la violencia es propia de aquellos que, situados en una posición intersticial interna, entienden las normas constitucionales como aquellas normas respecto a las cuales no cabe ni siquiera disentir en tanto que condiciones para la existencia misma de la comunidad política y, por ende, de un mundo ordenado. En consecuencia, la transgresión de las normas constitucionales es concebida como una amenaza para la continuidad del orden constitucional y, por consiguiente, para la pervivencia misma de la comunidad política.

Que el mundo construido por las normas definitorias constituyentes perdure en la medida en que esas normas son practicadas implica que es posible la no aceptación e, incluso, la violación de las mismas. Aun y partiendo de la presunción de la unanimidad en su aceptación social, esa posibilidad es completamente asumible por parte de los miembros de la comunidad, pues, para éstos, su falsación empírica no invalida su verdad como Idea, o si se prefiere, como proyecto político que define a la comunidad. Por otro lado, al ser esas normas concebidas por los miembros de la comunidad como enunciados (descriptivos) que constituyen su mundo, tal vulneración se concibe como una alteración inadmisible del orden "natural" de las cosas; las normas constitucionales conforman el ámbito de lo no-decidible, es decir, de lo "imposible" de decidir ${ }^{49}$, no porque no sea una opción real, sino porque "salirse" del orden constitucional conlleva la disolución del orden social, la destrucción de la comunidad política, la caída en el caos. De ahí que, respecto a las normas que definen la comunidad política, no admitan la disidencia. Pero el disidente no sólo es concebido como un agente inmoral desintegrador del orden político, sino que además es quien está equivocado; desde este segundo punto de vista, el problema radicaría en que no sabría quién es realmente y a qué mundo pertenece. A su vez, la negación de la identidad del disidente conlleva inevitablemente la negación de su proyecto político dirigido a la continuidad de la que considera su comunidad política y, ulteriormente, a la

encuentra en la imposición forzada su único recurso, ni, por lo tanto, el ámbito de lo que este autor califica como "la Política" (en mayúscula) queda constreñido a la actividad encaminada a alcanzar esa homogeneización mediante la fuerza.

49 Sobre la noción de "lo no-decidible", ver E. GARZÓN VALDÉS, "Representación y democracia”, Doxa, núm. 6, 1989, pp. 143-163. 
negación de su identidad (con la consiguiente falta de reconocimiento de derechos que tiende a situarlo en la "nuda vida" $\left.{ }^{50}\right)^{51}$ : no sólo no debería ser por su maldad, sino porque su existencia pone en cuestión el mundo constituido. El otro disidente sencillamente debería no existir.

El recurso a la vía violenta por parte de una comunidad que se sitúa en una posición intersticial interna se articula a través del denominado "estado de excepción". Se entiende por "estado de excepción" la situación de suspensión del ordenamiento jurídico frente a una situación en que la continuidad del orden constitucional se considerada amenazada, de forma que se levantan los constreñimientos que el ordenamiento jurídico impone sobre el Estado respecto al uso de la violencia. A la percepción de un estado como excepcional le sigue la adopción de medidas excepcionales (que contravienen la legalidad). Esa suspensión del ordenamiento jurídico se puede producir con base en un derecho de excepción (es decir, a una norma del ordenamiento jurídico que regula situaciones de excepcionalidad) o bien de facto (ya sea porque tal ordenamiento no contempla un derecho de excepción o, porque contemplándolo para algunos casos, no hay ningún artículo que prevea una situación concreta) ${ }^{52}$.

El estado de excepción genera una situación paradójica, pues sitúa al militante en una posición similar a la del disidente (esto es, en una posición intersticial). Y es que el propósito formal residiría en garantizar el cumplimiento de un orden constitucional que encuentra su despliegue en un orden jurídico que queda suspendido ${ }^{53}$, lo cual conlleva indirectamente la poten-

50 En torno a este concepto, ver las obras de G. AGAMBEN, Medios sin fin: Notas sobre la política, Valencia, Pre-Textos, 2001, y Homo sacer I: El poder soberano y la nuda vida, cit.

51 La noción de "disidente" aquí desarrollada enlaza con el concepto de "potencialidad" sobre el cual, según, B. GULLI, "The ontology and politics of exception”, en T. ZARTALOUDIS (ed.), Agamben and Law, Londres; Nueva York, Routledge, 2016, pp. 141-164, se fundamentaría el pensamiento de Agamben, y que tendría como consecuencia política el permanente estado de excepción característico de nuestros días. Ese enlace se podría exponer de la siguiente manera: en la medida en que el reconocimiento de derechos abre la posibilidad de que el disidente lleve a cabo conductas disidentes (ya gocen de amparo legal o no), la evitación de esa potencialidad justificaría la aplicación anticipada/preventiva de medidas restrictivas de derechos. La amenaza y la necesidad de respuesta se ubicaría en la potencialidad (en el ámbito de lo que las personas piensan y son), no en la actualización (en el ámbito de las conductas).

52 P. CRUZ, Estados excepcionales y suspensión de garantías, Madrid, Tecnos, 1984, pp. 17-35.

53 G. AGAMBEN, Estado de excepción: Homo sacer, II, 1, Valencia, Pre-textos, 2010. 
cial suspensión de los derechos y libertades que pudieran integrar el orden constitucional. De esta forma, la respuesta dada por el Estado puede perfectamente entrar en contradicción con el derecho de normalidad; de manera más precisa, el estado se excepción se caracteriza por posibilitar una respuesta y, simultáneamente, la contraria para un mismo supuesto de hecho, sin que quepa prever la reacción estatal ante un caso concreto. En definitiva, el fenómeno jurídico abandona el terreno de lo ordenado (ludus) para situarse en el ámbito de lo caótico (paidia).

Se pueden establecer algunas analogías y diferencias entre la suspensión de la actividad de jugar y la suspensión del orden jurídico. Por un lado, tanto la comunidad de jugadores, como la comunidad política se sitúan en una posición intersticial interna, suspendiendo la aplicación de las reglas de juego. Pero mientras que la persecución del objetivo del juego queda en suspenso temporalmente cuando la comunidad de jugadores se ubica en esa posición, no sucede lo mismo en el caso de la comunidad política bajo el estado de excepción: el Estado no deja de perseguir el mismo objetivo que en el estado de normalidad, el mantenimiento del orden constitucional; más bien, ahora se autoriza a hacer trampas. En palabras de Lazzeri y Reynié, cuando prima la razón de estado "1’Etat est comme un mauvais perdant qui parfois modifie les règles du jeu" ${ }^{\prime 5}$.

La adopción de medidas excepcionales encontraría su justificación en el estado de necesidad: la salvaguarda del todo necesitaría el sacrificio de una parte. Conviene subrayar que la necesidad remite, no a imperativos normativos, sino técnicos, es decir, a una cuestión de eficacia en términos de una relación medio-fin: las medidas adoptadas no se entienden propiamente como consecuencias normativas imputables a una conducta ilícita, sino como aquellas necesarias para conseguir el restablecimiento de un determinado estado de la realidad ${ }^{55}$. Así pues, los perjuicios causados por el uso de la violencia bajo el estado de excepción no se conciben propiamente como sanciones jurídicas que se imputan ante la transgresión de una obligación o una prohibición, sino como aquella respuesta considerada eficaz para restituir el estado de cosas anterior a una conducta o actividad que, en tanto que inválida o nula, nunca debería haberse producido. En otras palabras, la reacción del Estado bajo el

54 C. LAZZERI; D. REYNIÉ, La raison d'État: Politique et rationalité, Paris. Presses Universitaires de France, 1992, pp. 10. (trad.:"El Estado es como un mal perdedor que a veces modifica las reglas del juego". Traducción tomada de E. FERNÁNDEZ, Entre la razón de Estado y el Estado de derecho: la racionalidad política, Madrid. Dykinson, 1997, pp. 2.)

55 J. SEVILLA, "El estado de excepción", en Estudios sobre la Constitución española de 1978, Valencia, Universidad de Valencia, 1980, pp. 341-351. 
estado de excepción no es propiamente la respuesta última ante un acto indebido, sino ante la negativa de un agente a aceptar la invalidez o nulidad de las consecuencias de sus actos, esto es, a aceptar la imposibilidad (en un sentido ontológico) de las consecuencias de sus acciones.

Que la justificación de esas medidas radique en su "necesidad", y no en su justicia o en que sean la consecuencia jurídica debida, supone nuevamente dibujar la cuestión del mantenimiento del orden político-jurídico, no en términos propiamente normativos, sino más bien ontológico-institucionales. $Y$, nuevamente, el entrelazamiento de lo descriptivo y lo prescriptivo produce resultados paradójicos: la conformación de la realidad a través del recurso a una violencia no reglada no se presenta como una manera de forzamiento de la realidad, sino como medidas "realistas" encaminadas a que la comunidad se adecúe a la realidad, una realidad que, eso sí, consiste en la imagen construida por las normas definitorias constituyentes que pretenden imponerse mediante el recurso a esa violencia no reglada. El problema se plantea como de necesidad de adaptación al mundo, pero en realidad son las leyes de ese mundo ilusorio las que se consideran amenazadas.

Como se viene comentando, la identidad comunitaria se basa, teóricamente, en la aceptación de las reglas de juego comunitarias, con la consiguiente inmersión de los aceptantes en el mundo construido por esas reglas, de tal forma que ese mundo pasa a presentarse para sus integrantes como un sistema de enunciados descriptivos y constitutivos, cuya vulneración acarrea la invalidez o nulidad, pero no propiamente la imposición de sanciones negativas. El hecho de que los textos constitucionales se presenten como expresión de un consenso social supuestamente unánime en torno a la identidad comunitaria explicaría la práctica ausencia de normas constitucionales en las cuales se establezcan sanciones negativas. Así, de manera análoga a lo que sucede en la actividad de jugar, los órdenes constitucionales no estipulan normas de sanción contra aquellos que se considera que han violentado las reglas de juego constitucional, ya sea porque no viene estipulada en el ordenamiento jurídico (de nuevo, aquí, de manera similar a lo que ocurre en reglas de los juegos), o porque, viniendo recogida, hace referencia sólo a la adopción de las medidas "necesarias" para mantener el orden constitucional. El levantamiento de cualquier límite normativo en el uso de la violencia, ya sea de facto o en base a las escasísimas normas constitucionales que habilitan el uso de la violencia, supone la ultima ratio ${ }^{56}$ del Estado.

56 F. QUESADA, Ultima ratio regis: Control y prohibición de las armas desde la antigüedad a la edad moderna, Madrid, Polifemo, 2009, pp. 392-93; R. WENDT, "The principle of 'ultima 
Lo anterior no supone negar la existencia de normas en los ordenamientos jurídicos dirigidos a castigar las transgresiones que se consideran vulneraciones graves de valores y normas constitucionales ${ }^{57}$, incluidas las transgresiones contra el orden constitucional en sí mismo. Dentro del ordenamiento jurídico español, a esa lógica responde, por ejemplo, la configuración del delito de rebelión recogido en el artículo $472 \mathrm{CP}$.

En los Estados de derecho, ese tipo de normas no formarían parte del derecho de excepción. En efecto, conforme a la lógica del Estado de derecho, la persecución de ideas políticas es contraria a la lógica de ese tipo de sistemas. Ello se traduce en la exigencia del empleo de violencia física (y adecuada al tipo de actividad) como elemento configurador del ilícito. De ahí que este tipo de normas de sanción negativa no vengan recogidas en las constituciones, sino que se relegan a la legislación de rango inferior, de manera destacada el derecho penal, al ser éste el ámbito en que se regula la reacción del Estado frente a conductas y actividades violentas. De esta forma, si la reacción del Estado se ajusta a la norma penal, la capacidad de respuesta estatal alcanza, no a cualquier actividad dirigida a socavar el orden constitucional, sino sólo a aquellas conductas que ejercen una violencia propia de las rebeliones: no se castiga al disidente por muy amenazante que se considere su actividad para la continuidad del orden constitucional, sino a quien se alza violentamente. La lógica del Estado de derecho exige que la respuesta al disidente que canaliza sus demandas, no necesariamente conforme a derecho, pero sí pacíficamente, se articule políticamente, en ningún caso penalmente. Aún de otra manera: no se admite cualquier respuesta estatal en función de su necesidad, sino que se exige que el Estado ajuste su respuesta a derecho y aplique, ahora sí, la sanción jurídicamente estipulada sólo en el caso de que se pruebe la concurrencia de todos los elementos que configuran el ilícito.

ratio' and/or the principle of proportionality", Oñati Socio-Legal Series, vol. 3, núm. 1, 2013, pp. 84. El origen de esta expresión se remontaría a la inscripción serigrafiada en los cañones franceses a partir de los últimos años de la Guerra de los Treinta Años por orden del cardenal Richelieu, práctica que habría adoptado Federico el Grande de Prusia a partir de 1742. Desde hace más de 250 años, a partir de Carlos III, y hasta la actualidad, esa práctica fue igualmente adoptada por la monarquía española, siendo además el lema del cuerpo de artillería en la actualidad (ver A. SANZ, "Editorial", Memorial de Artillería, núm. 170 vol. 1, 2014, pp. 2.

57 G. QUINTERO et altri, "La construcción del bien jurídico protegido a partir de la Constitución", en G. QUINTERO (dir.), J. JARIA (coord.), Derecho penal constitucional, Valencia, Tirant lo Blanch, 2015, pp. 84-133. 
Que ese tipo de normas penales no formen parte del derecho de excepción implica que no puedan ser entendidas como normas constitucionales (en el sentido que aquí se ha dado a este concepto). En la medida en que el Estado se adecúe a derecho en la aplicación de ese tipo de artículos, esas normas son concebidas como normas de sanción negativa: ni ellas por sí mismas cumplen la función de definir a la comunidad política, ni tampoco operarían como la respuesta "necesaria" por parte del Estado frente a quienes cuestionan aquellas normas que integrarían el orden constitucional.

Sólo si el Estado aplicara esas normas penales conforme a la lógica del estado de excepción (es decir, desde una posición intersticial interna) de tal forma que se utilizaran para criminalizar cualquier conducta considerada amenazante, incluidas las pacíficas (por ejemplo, mediante la redefinición de "violencia" como, potencialmente, cualquier acción de oposición al orden constitucional, sin que importase si ha habido actos violentos o no, o de si la violencia ejercida es adecuada al tipo delictivo), entonces pasarían a formar parte de facto del derecho de excepción: el acto mismo de disentir sí sería entendido como una forma de violencia. En ese caso, y más allá de las apariencias, el Estado no actuaría realmente con sujeción al ordenamiento jurídico.

La imposición mediante el recurso a la violencia en caso de transgresión de las normas constitucionales plantea los dos siguientes problemas.

Primer problema. El recurso a la violencia irrestricta de cara al mantenimiento del orden constitucional conduce a dos consecuencias de difícil encaje entre sí. Por un lado, la reacción violenta irrestricta se justifica en que el orden constitucional estaría conformado por aquellos elementos que integran un supuesto consenso social unánime, unanimidad que hallaría su fundamento en el hecho de que, supuestamente, las normas constitucionales expresarían el orden "natural" del mundo, fuera del cual resultaría imposible la vida comunitaria. Pero si el orden constitucional se entiende como la descripción de las leyes de una realidad indisponible, como sucede si se interpretan desde una perspectiva interna, entonces la reacción violenta no sólo debería resultar fútil (ninguna acción humana puede transformar las leyes de la naturaleza), sino además totalmente innecesaria (si hay unanimidad, no hay necesidad de imposición mediante la violencia). Esa contradicción se sustenta sobre la falsa premisa de que el orden constitucional responde a una realidad objetiva y a un consenso social unánime: el hecho fáctico es la falta de unanimidad en la aceptación de las reglas de juego constitucionales. 
Segundo problema. Los textos constitucionales se presentan como normas que constituyen un orden político y social basado en relaciones de convivencia y no en la imposición mediante la fuerza. Por consiguiente, el recurso a la violencia resulta problemático porque dificulta presentar el orden constitucional como el marco de convivencia político y social.

El uso de la violencia contra aquellos que deciden no liberarse de la tensión que domina la decisión dirigida hacia objetivos serios contemplados en la constitución (es decir, contra quienes consideran las normas constitucionales como enunciados prescriptivos y, por lo tanto, susceptibles de ser transgredidos, o, aún de otra manera, contra quienes ya no quieren "jugar" conforme a las reglas del orden constitucional establecido) plantea problemas en relación con la consecución del objetivo último, y que no es otro que el restablecimiento del orden constitucional. El problema radica en que, si las constituciones son, supuestamente, la expresión del consenso fundamental de los miembros de una comunidad, el restablecimiento del orden constitucional sólo se puede conseguir con la aceptación voluntaria de tal orden por parte de quienes han expresado su voluntad de salirse del juego. Que el orden construido por las normas constitucionales se pueda presentar como un hecho dado, y no como un proyecto político partidista que necesita forzar el mundo presente para su implementación, depende del grado de aceptación de tales reglas. Cabe esperar que la imposición de un orden constitucional mediante la coacción o la violencia conduzca a la toma de conciencia de su carácter autoritario y, por ende, de su deslegitimación por aquellos que sufren dicha violencia.

\section{CONCLUSIONES. ESTADO DE DERECHO Y DERECHO A LA AUTODETERMINACIÓN}

La actividad de jugar regulada por las reglas de los juegos se caracteriza por su carácter voluntario (se sustenta en la aceptación del sometimiento a las reglas) y lúdico (no seriedad de los objetivos planteados por el juego en relación a la vida cotidiana). Pero que los objetivos del ámbito de lo lúdico sean triviales no implica que, en tanto que voluntaria, la actividad de jugar se sostenga sobre una serie de valores que no son triviales, a saber, la libertad y la igualdad. Una consecuencia de lo anterior es que la aceptación voluntaria de jugar en el momento constituyente no supone la obligatoriedad de permanecer en la actividad de jugar: el derecho de salida está inherentemen- 
te vinculado al carácter voluntario del sometimiento a las reglas del juego. La actividad constituyente de las comunidades políticas recogida en los órdenes constitucionales mantiene una relación ambivalente con la actividad lúdica. Por un lado, tradicionalmente se ha situado en el terreno de lo sacro, caracterizado por su carácter trascendente (independiente de la aceptación voluntaria de sus miembros) y la seriedad de los objetivos y la actividad misma (constitución de un mundo ordenado -o de una comunidad políticafrente a la posibilidad de una situación de anarquía). Por otro lado, en los Estados de Derecho los órdenes constitucionales encuentran su legitimidad y pueden presentarse como reglas de convivencia en la medida en que los miembros de la comunidad aceptan someterse voluntariamente al ordenamiento jurídico. La tensión aparece cuando se sostiene, al mismo tiempo, el carácter obligatorio (sacro) y voluntario (lúdico) de un orden constitucional: paradójicamente, se justifica el uso de la violencia física contra los disidentes que se considera ponen en peligro el orden constitucional, con base en un supuesto consenso resultado de la aceptación voluntaria de ese mismo orden, suposición que remite a una imagen distorsionada y homogeneizadora de la sociedad que, en realidad, impone al disidente el deber de sometimiento al orden constitucional sin que importe su voluntad.

Se presenta así una disyuntiva. Se puede optar por la sacralización del orden constitucional, la negación del derecho de salida (en otras palabras, el derecho a la autodeterminación) y, por consiguiente, el mantenimiento del mismo mediante el uso de la violencia. Pero entonces ese orden deja de ser la expresión de un proyecto compartido por una comunidad política, las normas constitucionales pierden su legitimidad y ya no pueden presentarse como normas de convivencia. Esta es la lógica de los regímenes autoritarios y la razón de Estado. O también cabe optar por la ludificación del orden constitucional, esto es, por el reconocimiento del derecho de salida como norma constitutiva del orden constitucional (oportunamente desarrollado en la legislación ordinaria), la inmanencia y la voluntariedad del orden constitucional, en coherencia con la lógica del Estado de Derecho.

A mi parecer, lo deseable sería que las comunidades políticas se asemejaran, en la mayor medida posible, al modo cómo funcionan las comunidades de jugadores. De forma más precisa, lo deseable sería que la inevitable e imprescindible sacralización del orden constitucional se constriñera a los valores que aseguran la libre integración en la comunidad, lo cual implica un orden basado en la libertad y el respeto a y la valoración de la diferencia, así 
como en el derecho a salirse de ella. En otras palabras, la integración basada en la igualdad en la diferencia (o, si se prefiere, la convivencia basada en la libre aceptación) debería erigirse en principio interpretativo de los órdenes constitucionales. Esta opción no es sino un alegato en favor de la profundización en el proceso de secularización (o desacralización) de las comunidades políticas.

JuAN-RAMÓN FALladA-García-VALLE Filosofía del Derecho Universitat Rovira i Virgili Avinguda Catalunya 35

Tarragona 43002 e-mail:juanramon.fallada@urv.cat 